\title{
Itching in Patients with Chronic Hand Eczema: Data from the CARPE Registry
}

\author{
Linda Ruppert ${ }^{\mathrm{a}} \quad$ Christian Apfelbacher $^{\mathrm{a}, \mathrm{b}}$ Sonja Molin ${ }^{\mathrm{c}} \quad$ Andrea Bauer $^{\mathrm{d}} \mathrm{e}$ \\ Vera Mahlerg Jochen Schmitte, ${ }^{\mathrm{f}}$ Peter Elsner $^{\mathrm{h}}$ Thomas L. Diepgen $^{\mathrm{a}}$ \\ Elke Weisshaar ${ }^{a}$
}

\begin{abstract}
aDepartment of Clinical Social Medicine, Occupational and Environmental Dermatology, University Hospital, Ruprecht Karls University, Heidelberg; ${ }^{b}$ Medical Sociology, Institute of Epidemiology and Preventive Medicine, University of Regensburg, Regensburg; ' Department of Dermatology and Allergy, Ludwig Maximilian University, Munich; 'Department of Dermatology and 'University Allergy Center, University Hospital Carl Gustav Carus, Technical University Dresden, and ${ }^{\mathrm{f} C e n t e r}$ for Evidence-Based Healthcare, Medical Faculty Carl Gustav Carus, Technical University Dresden, Dresden; 9 Department of Dermatology, University Hospital of Erlangen, Friedrich Alexander University, Erlangen; ${ }^{\text {h}}$ Department of Dermatology and Dermatological Allergy, Friedrich Schiller University, Jena, Germany
\end{abstract}

\section{Key Words}

Atopy - Chronic hand eczema - Dermatology Life Quality Index · Eczema - Itch · Pruritus · Quality of life · CARPE registry

\begin{abstract}
Background: Itching is a leading symptom of chronic hand eczema (CHE) having a great impact on patients. The determinants of itching in CHE are unclear. Objective: We performed a cross-sectional analysis investigating factors associated with the presence and severity of itch in CHE patients from the CARPE registry. Methods: We present baseline data on itch in relationship with sociodemographic factors, severity of $\mathrm{CHE}$, atopy, contact allergy, treatment and patientreported outcomes including health-related quality of life (HRQoL). Results: Of 1,051 patients with $\mathrm{CHE}, 78.1 \%$ reported itching. Significant positive associations with itching were observed for younger age groups (17-25 and 26-45 years), for moderate, severe and very severe CHE and for small/moderate impairment in HRQoL. Atopic skin diathesis, hardly being able to realize treatment recommendations
\end{abstract}

\section{KARGER}

www.karger.com/drm
E-Mail karger@karger.com and very or extremely large impairments in $\mathrm{HRQ}$ L L were associated with itch severity. Conclusion: Taking the identified variables into account may help identify vulnerable groups most affected by (severe) itch.

(c) 2014 S. Karger AG, Basel

\section{Introduction}

Hand eczema (HE) is a frequent and complex disease in terms of morphology, location, and especially of etiology $[1,2]$. In contrast to acute HE, chronic hand eczema (CHE) is characterized by longer disease duration or recurrent episodes and is frequently refractory to topical anti-inflammatory treatment. Patients with CHE complain about a variety of symptoms such as itching, burning, stinging and pain. Often itching is the dominating symptom, but other dermatoses and diseases may also present with itching of the hands, requiring a precise diagnostic

\section{Ruppert and C. Apfelbacher share first authorship.}

(c) 2014 S. Karger AG, Basel
$1018-8665 / 14 / 2292-0146 \$ 39.50 / 0$ 
procedure of this symptom [3]. However, little is known about factors associated with the occurrence and severity of itching in CHE. Previous studies have focused on cofactors of itching in patients with various dermatological diseases $[4,5]$ or in samples drawn from the general population $[6,7]$. An ongoing cross-sectional study in dermatological departments of 13 European countries investigates the prevalence and intensity of itch in dermatological patients. HE was reported to be among the most frequent diseases in patients suffering from (acute) itch [8].

The CARPE registry has been set up to evaluate sociodemographic and clinical characteristics as well as patient-reported outcomes and treatment modalities in patients affected by CHE. The aim of this data analysis was to identify factors associated with itch and itch severity using baseline data from all CHE patients included in CARPE.

\section{Materials and Methods}

The CARPE (German acronym: Chronisches HandekzemRegister zum Patienten-Langzeitmanagement, meaning chronic hand eczema registry on long-term patient management) registry was established in 2009 as a prospective observational patient cohort study. Eligible patients are patients diagnosed with CHE (defined as disease duration $\geq 3$ months or $>2$ flares within the previous 12 months), with previous treatment with topical corticosteroids, no long-lasting healing under adequate topical treatment including corticosteroids and no other dominating active severe skin diseases or acute skin infection. Data are collected through dermatological examinations and patient questionnaires, e.g. through the Physician Global Assessment (PGA) and the Dermatology Life Quality Index (DLQI). The design and methodology of the CARPE registry have been previously described in detail $[9,10]$ (for further details see also http://carpe.dermis.net). Ethical approval was obtained from the University of Heidelberg, Germany (No. S-433/2008). The study was established according to the guidelines of good clinical practice. Patients gave their written informed consent.

This analysis is based on data from the physicians' documentation as well as patient data assessed at the first examination (baseline examination). We performed a cross-sectional analysis $(\mathrm{n}=$ 1,051) investigating factors associated with the presence and the severity of itch in patients with CHE.

\section{Primary Outcome}

Current itching was assessed by the physician by means of a verbal rating scale in four categories (none, mild, moderate and severe). Itching was evaluated once at baseline examination. 'Mild' and 'moderate' were collapsed into one category. The following two variables were used as outcome variables: (1) presence of itch (yes vs. no); (2) severity of itch (severe vs. mild/moderate).

\section{Sociodemographic and Clinical Data}

The following variables were explored in correlational analyses (fig. 1): (1) sex (male, female); (2) age (grouped into four catego-

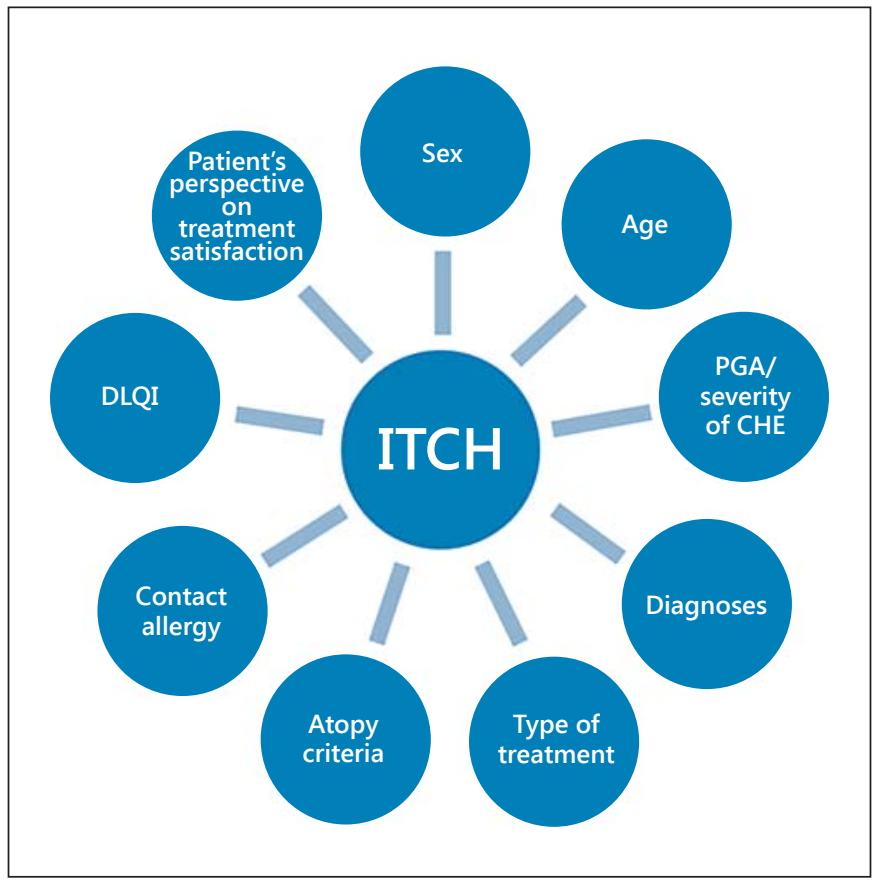

Fig. 1. Variables associated with itch in patients with $\mathrm{CHE}$ explored in correlation analysis.

ries: 17-25 years, $26-45$ years, $46-64$ years, $\geq 65$ years); (3) severity of CHE (assessed by PGA, supported by the use of a validated photographic guide [11] and rated on a five-point Likert scale: very severe, severe, moderate, almost clear, clear); (4) self-assessed severity of $\mathrm{CHE}$, rated on a visual analogue scale ranging from 0 (clear) to 10 (very severe); (5) diagnosis of CHE (due to a frequent clinical overlap seen in CHE, multiple diagnoses were possible); (6) atopy (yes vs. no; documented according to the Erlangen Atopy Score [12]); (7) contact allergy (type IV allergy yes vs. no); (8) reported treatment of $\mathrm{CHE}$ in the 12 months prior to inclusion into the registry (topical treatment yes vs. no, UV phototherapy yes vs. no, systemic therapy yes vs. no); (9) patient-reported outcomes: (a) therapy perceived as burdensome, therapy being timeconsuming and experience of unpleasant side effects, rated on a four-point Likert scale (not at all, a little, a lot, very much); (b) realization of treatment recommendations, rated on a four-point Likert scale (fully, mostly, hardly, not at all); (c) health-related quality of life (HRQoL), measured using the DLQI, ranging from no impairment to very severe impairment (0-30) and grouped into 5 categories according to Hongbo et al. [13] $(0-1=$ no effect on patient's life, $2-5=$ small effect, $6-10=$ moderate effect, $11-20$ = very large effect, $21-30=$ extremely large effect).

\section{Statistical Analyses}

A Microsoft Access 2003 database was used for data entry. Statistical analyses were performed using SPSS (version 20) for Windows. Nominal and ordinal data were analyzed by computing absolute (n) and relative frequencies (\%). Continuous variables were analyzed by computing mean and standard deviation (SD). Statistical analysis was done in two steps. First $\chi^{2}$ statistics were used to iden- 
Table 1. Descriptive analysis of factors associated with itch in patients with CHE in the whole sample

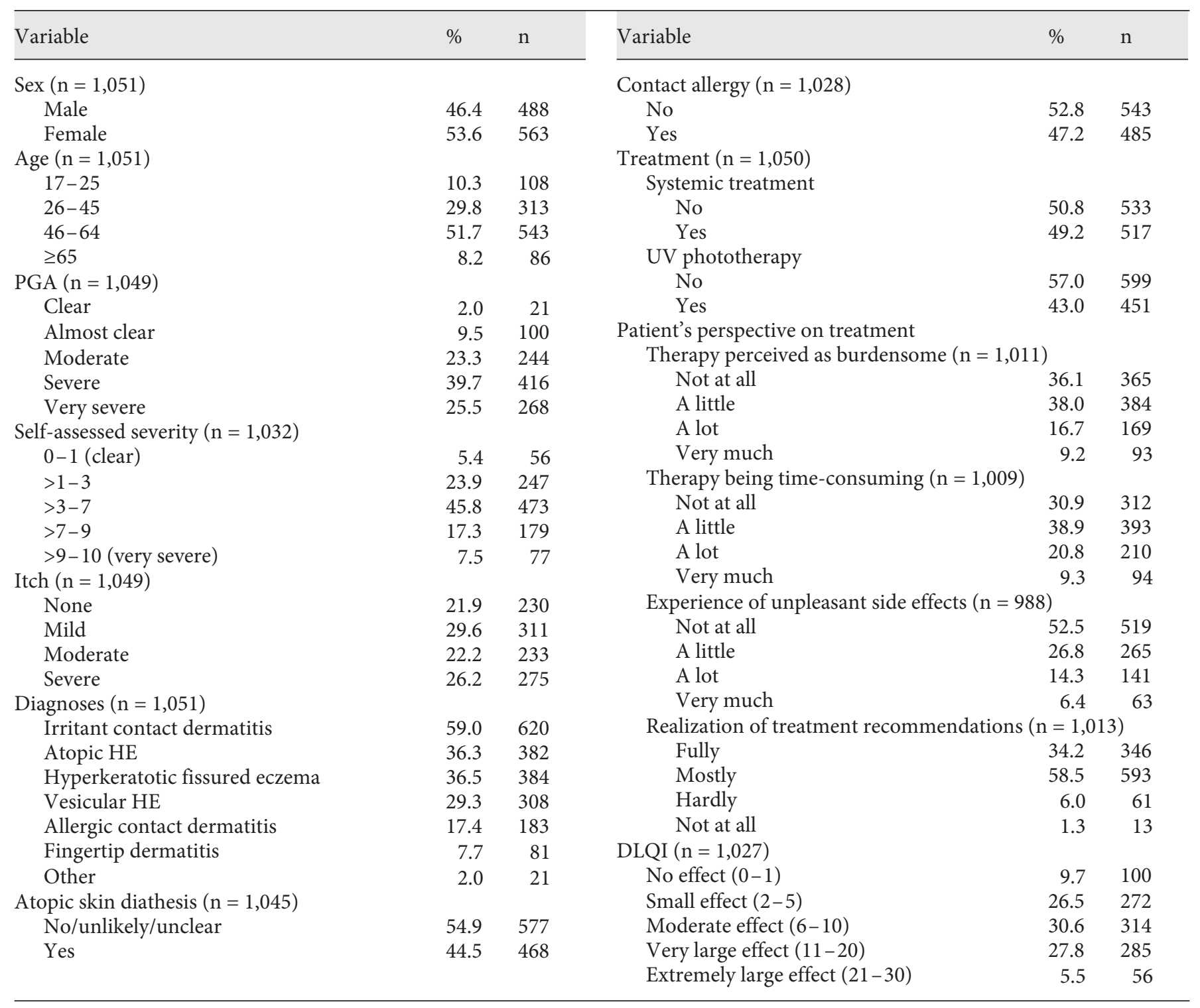

tify variables that were significantly associated with itch and severity of itch in univariate analysis. $\mathrm{p}$ values $<0.05$ were considered significant. In a second step those variables that were significantly associated with the presence of itch and itch severity respectively were entered into multivariate logistic regression models. Adjusted odds ratios with corresponding $95 \%$ confidence intervals were computed.

\section{Results}

A description of the sample in terms of sociodemographic and clinical characteristics is provided in table 1. More than half of the patients were female. The mean age was around 48 years (SD 13.8). Around 78\% $(n=819)$ of the patients were affected by itch. Of those affected by the symptom, $38 \%(n=311)$ reported mild, $28 \%(n=233)$ moderate and $34 \%(n=275)$ severe itching.

\section{Factors Associated with the Presence of Itch}

Univariate Analysis. As shown in table 2, we found significant associations between the presence of itch and sex, age, PGA, self-assessed severity of $\mathrm{CHE}$, atopic skin diathesis, therapy perceived as burdensome, experience of unpleasant side effects, realization of treatment recommendations and HRQoL. 
Table 2. Presence of itch according to investigated variables (univariate analysis)

\begin{tabular}{|c|c|c|c|c|c|}
\hline $\operatorname{Sex}(n=1,049)$ & & 0.031 & \multicolumn{2}{|c|}{ Systemic treatment } & \\
\hline Male & $75.1(365)$ & & \multicolumn{2}{|c|}{12 months prior to inclusion $(\mathrm{n}=1,048)$} & 0.247 \\
\hline Female & $80.6(454)$ & & No & $79.5(423)$ & \\
\hline Age $(n=1,048)$ & & 0.001 & Yes & $76.6(395)$ & \\
\hline $46-64$ & $75.3(408)$ & & No & $79.9(477)$ & \\
\hline$\geq 65$ & $70.9(61)$ & & Yes & $75.6(341)$ & \\
\hline PGA $(n=1,048)$ & & $<0.001$ & \multicolumn{2}{|c|}{ Therapy perceived as burdensome $(\mathrm{n}=1,009)$} & 0.001 \\
\hline Clear & $38.1(8)$ & & Not at all & $73.9(269)$ & \\
\hline Almost clear & $51.0(51)$ & & A little & $77.3(296)$ & \\
\hline Moderate & $71.2(173)$ & & A lot & $84.0(142)$ & \\
\hline$>1-3$ & $64.4(159)$ & & A lot & $78.1(164)$ & \\
\hline$>3-7$ & $83.0(391)$ & & Very much & $85.1(80)$ & \\
\hline$>7-9$ & $88.8(159)$ & & \multicolumn{2}{|c|}{ Experience of unpleasant side effects $(n=986)$} & 0.038 \\
\hline$>9-10$ (very severe) & $88.3(68)$ & & Not at all & $78.7(407)$ & \\
\hline Atopic skin diathesis $(\mathrm{n}=1,043)$ & & 0.004 & A little & $74.0(196)$ & \\
\hline No/unlikely/unclear & $74.7(430)$ & & A lot & $83.7(118)$ & \\
\hline Yes & $82.0(383)$ & & Very much & $87.3(55)$ & \\
\hline Contact allergy $(n=1,026)$ & & 0.466 & \multicolumn{2}{|c|}{ Realization of treatment recommendations $(n=1,020)$} & $<0.001$ \\
\hline No & $77.1(417)$ & & Fully & $68.8(161)$ & \\
\hline Yes & $79.0(383)$ & & Mostly & $77.8(360)$ & \\
\hline Diagnoses $(n=1,049)$ & & & Hardly & $84.4(217)$ & \\
\hline
\end{tabular}

Multivariate Analysis. Findings from multivariate analyses (table 3 ) revealed significant positive associations between age groups $17-25$ years and $26-45$ years, very severe, severe or moderately severe $\mathrm{CHE}$ as well as a moderate or very large impairment of QoL and itch. The association between presence of itch and DLQI clearly decreased after adjustment. A significant inverse association was found between experiencing unpleasant side effects 'a little' and itch.

Factors Associated with the Severity of Itch

Univariate Analysis. We found significant associations between the severity of itch and PGA, self-assessed sever- ity of $\mathrm{CHE}$, atopic skin diathesis, therapy perceived as burdensome, therapy perceived as time-consuming, realization of treatment recommendations and DLQI (table 4).

Multivariate Analysis. Multivariate logistic regression (table 5) revealed that the direction of association remained the same for the variables PGA, atopy, experience of unpleasant side effects and DLQI. However, only the presence of atopic skin diathesis, hardly any realization of treatment recommendation as well as a very and extremely large impairment of QoL were significantly associated with severity of itch. 
Table 3. Results from multivariate logistic regression (outcome: presence of itch)

\begin{tabular}{|c|c|}
\hline Variable & $\begin{array}{l}\text { Adjusted OR } \\
(95 \% \mathrm{CI})\end{array}$ \\
\hline \multicolumn{2}{|l|}{$\operatorname{Sex}(n=1,049)$} \\
\hline Male & 1.0 \\
\hline Female & $1.29(0.91-1.84)$ \\
\hline \multicolumn{2}{|l|}{ Age $(n=1,048)$} \\
\hline $17-25$ & $4.68(1.76-12.46)$ \\
\hline $26-45$ & $2.02(1.05-3.87)$ \\
\hline $46-64$ & $1.65(0.90-3.03)$ \\
\hline$\geq 65$ & 1.0 \\
\hline \multicolumn{2}{|l|}{ PGA $(n=1,048)$} \\
\hline Clear & 1.0 \\
\hline Almost clear & $2.43(0.81-7.31)$ \\
\hline Moderate & $4.43(1.51-13.02)$ \\
\hline Severe & $6.14(2.07-18.16)$ \\
\hline Very severe & $9.34(2.91-29.97)$ \\
\hline \multicolumn{2}{|l|}{ Self-assessed severity $(\mathrm{n}=1,030)$} \\
\hline $0-1$ (clear) & 1.0 \\
\hline$>1-3$ & $1.00(0.50-2.00)$ \\
\hline$>3-7$ & $1.70(0.81-3.58)$ \\
\hline$>7-9$ & $2.46(0.97-6.24)$ \\
\hline$>9-10$ (very severe) & $2.08(0.63-6.87)$ \\
\hline \multicolumn{2}{|l|}{ Atopic skin diathesis $(\mathrm{n}=1,043)$} \\
\hline No/unlikely/unclear & 1.0 \\
\hline Yes & $1.29(0.90-1.86)$ \\
\hline \multicolumn{2}{|c|}{ Therapy perceived as burdensome $(n=1,009)$} \\
\hline Not at all & 1.0 \\
\hline A little & $1.16(0.76-1.78)$ \\
\hline A lot & $1.47(0.77-2.80)$ \\
\hline Very much & $2.48(0.92-6.67)$ \\
\hline \multicolumn{2}{|c|}{ Experience of unpleasant side effects $(n=986)$} \\
\hline Not at all & 1.0 \\
\hline A little & $0.51(0.33-0.79)$ \\
\hline A lot & $0.58(0.30-1.14)$ \\
\hline Very much & $0.51(0.18-1.44)$ \\
\hline \multicolumn{2}{|c|}{ Realization of treatment recommendations $(\mathrm{n}=1,020)$} \\
\hline Fully & 1.0 \\
\hline Mostly & $1.18(0.82-1.71)$ \\
\hline Hardly & $2.68(0.76-9.41)$ \\
\hline Not at all & $0.44(0.12-1.63)$ \\
\hline \multicolumn{2}{|l|}{ DLQI $(n=1,025)$} \\
\hline No effect $(0-1)$ & 1.0 \\
\hline Small effect $(2-5)$ & $1.39(0.80-2.41)$ \\
\hline Moderate effect $(6-10)$ & $1.87(1.03-3.41)$ \\
\hline Very large effect $(11-20)$ & $2.05(1.02-4.10)$ \\
\hline Extremely large effect $(21-30)$ & $2.84(0.83-9.79)$ \\
\hline
\end{tabular}

$\mathrm{CI}=$ Confidence interval; $\mathrm{OR}=$ odds ratio. Bold indicates $\mathrm{p}<0.05$.

\section{Discussion}

To our knowledge this is the first study investigating the prevalence and severity of itch in patients affected by CHE. The CARPE registry provides data on sociodemographic, clinical and treatment-related characteristics of patients with $\mathrm{CHE}$, which allows the investigation of cofactors of itch in CHE patients.

\section{Presence of Itch}

Our study showed that younger patients were more likely to report itching than older participants, with patients aged 17-25 years being most affected by itch, followed by the age group 26-45 years. This is in contrast to most findings from previous studies on itch, where older people (especially those between 50 and 60 years) tended to be more affected by itch $[4,6,7,14]$. One population-based study on chronic itch from Germany found a significant positive association between itch and the age group 31-40 years [7]. Results from our multivariate analysis did not show a significant difference between the presence of itch and sex, meaning that women and men with $\mathrm{CHE}$ are equally affected by itch. This is in contrast to results from most of the studies on itch considering sex [4, 5, 15-17]. A cross-sectional study with adults on self-reported skin morbidity in Oslo, Norway showed that women reported itching more often than men throughout all age groups [15].

Dermatologist-assessed severity of CHE was significantly associated with the presence of itch in a linear manner. Since no studies focusing on the presence and severity of itch in patients with HE have yet been conducted, further evidence is needed to confirm our results.

Our results show that the experience of unpleasant side effects indicated by the patients as 'a little' was associated with less itch. Patients reporting little experience of unpleasant side effects may be on effective treatment not imposing a heavy burden on them. If this is the case, itch may also be well controlled or not present. However, this remains speculative and the finding needs to be verified in future studies.

Moderate and extremely large effects on QoL, measured by the DLQI, were significantly associated with the presence of itch in patients with CHE. A study analyzing different dermatological diseases found a significant correlation between the presence of itch and a lower QoL measured by DLQI [18]. A Turkish study investigated a significant relationship between itch and DLQI scores $\geq 10$ in psoriasis patients [19]. Patients affected by pemphigus vulgaris showed significantly increased DLQI scores when itching was reported [20]. Similar results 
Table 4. Severity of itch according to the investigated variables (univariate analysis)

\begin{tabular}{|c|c|c|c|c|c|}
\hline Male & \multirow{2}{*}{\multicolumn{2}{|c|}{$\begin{array}{l}31.0(113) \\
35.7(162)\end{array}$}} & \multicolumn{2}{|c|}{12 months prior to inclusion $(\mathrm{n}=818)$} & \multirow[t]{2}{*}{0.385} \\
\hline Female & & & \multicolumn{2}{|c|}{ No $\quad 32.3(154)$} & \\
\hline Age $(n=818)$ & & 0.781 & Yes & $35.2(120)$ & \\
\hline $46-64$ & $32.4(132)$ & & A little & $26.7(79)$ & \multirow{3}{*}{$<0.001$} \\
\hline$\geq 65$ & $37.7(23)$ & & A lot & $28.9(41)$ & \\
\hline PGA $(n=818)$ & & $<0.001$ & Very much & $53.6(45)$ & \\
\hline Clear & $25.0(2)$ & & \multicolumn{2}{|c|}{ Therapy being time-consuming $(\mathrm{n}=787)$} & \multirow[t]{3}{*}{0.010} \\
\hline Almost clear & $17.6(9)$ & & Not at all & $35.5(87)$ & \\
\hline Moderate & $19.7(34)$ & & A little & $25.8(77)$ & \\
\hline$>1-3$ & $18.2(29)$ & & A little & $33.7(66)$ & \\
\hline$>3-7$ & $32.2(126)$ & & A lot & $32.2(38)$ & \\
\hline$>7-9$ & $42.1(67)$ & & Very much & $49.1(27)$ & \\
\hline$>9-10$ (very severe) & $63.2(43)$ & & \multicolumn{2}{|c|}{ Realization of treatment recommendations $(\mathrm{n}=792)$} & \multirow[t]{4}{*}{$<0.001$} \\
\hline \multicolumn{2}{|l|}{ Atopic skin diathesis $(n=813)$} & \multirow[t]{3}{*}{0.004} & Fully & $27.2(70)$ & \\
\hline No/unlikely/unclear & $28.8(124)$ & & Mostly & $32.8(154)$ & \\
\hline Yes & $38.4(147)$ & & Hardly & $52.6(30)$ & \\
\hline \multicolumn{2}{|l|}{ Contact allergy $(n=800)$} & \multirow[t]{4}{*}{0.580} & Not at all & $66.7(6)$ & \\
\hline No & $32.6(136)$ & & DLQI $(\mathrm{n}=798)$ & & \multirow[t]{3}{*}{$<0.001$} \\
\hline Yes & $34.5(132)$ & & No effect $(0-1)$ & $14.8(8)$ & \\
\hline Systemic treatment & & & Small effect $(2-5)$ & $20.9(40)$ & \\
\hline
\end{tabular}

were found in psoriatic patients with itch, who had significantly decreased HRQoL compared to patients not affected by itch [21]. A cross-sectional study with patients affected by systemic sclerosis from Canada measured QoL according to the 36-Item Short Form Health Survey. Patients suffering from pruritus had a significantly greater negative impact on QoL than patients without pruritus [22]. A cross-sectional study in $13 \mathrm{Eu}-$ ropean countries with 250 consecutive patients and 125 healthy controls demonstrated that patients reporting itch were more depressed than those without itch, had more anxiety and a larger impact on QoL measured by the DLQI [23].

\section{Severity of Itch}

Our study demonstrates that patients with atopy seem to be more likely to suffer from a severe form of itching than patients with no or an uncertain atopy. It is well known that atopic hand dermatitis is very frequently accompanied by itch, but so far there are no studies that specifically address this issue. A web-based questionnaire study on itch characteristics showed that atopic dermatitis responders experienced itch more frequently and more intensely when compared to subjects suffering from psoriasis [24]. In patients with occupational CHE, those with irritant contact dermatitis reported significantly less intense itching than patients with irritant-induced atopic HE [16]. Patients with severe CHE reported more intense itching than patients with non-severe CHE, and individuals with atopic dermatitis had higher visual analogue scale scores for itch than patients with exclusive HE [16]. This confirms our results showing a significant association between atopic diathesis and severe itch. 
Table 5. Results from multivariate logistic regression (outcome: severe itching)

\begin{tabular}{|c|c|}
\hline Variable & $\begin{array}{l}\text { Adjusted OR } \\
(95 \% \mathrm{CI})\end{array}$ \\
\hline \multicolumn{2}{|l|}{ PGA $(n=818)$} \\
\hline Clear & 1.0 \\
\hline Almost clear & $0.99(0.10-10.27)$ \\
\hline Moderate & $0.89(0.09-8.74)$ \\
\hline Severe & $1.26(0.13-12.24)$ \\
\hline Very severe & $2.16(0.22-21.06)$ \\
\hline \multicolumn{2}{|l|}{ Self-assessed severity $(n=808)$} \\
\hline $0-1$ (clear) & 1.0 \\
\hline$>1-3$ & $0.96(0.28-3.29)$ \\
\hline$>3-7$ & $1.40(0.41-4.79)$ \\
\hline$>7-9$ & $1.37(0.38-4.50)$ \\
\hline$>9-10$ (very severe) & $2.49(0.62-10.01)$ \\
\hline \multicolumn{2}{|l|}{ Atopic skin diathesis $(\mathrm{n}=813)$} \\
\hline No/unlikely/unclear & 1.0 \\
\hline Yes & $1.43(1.01-2.03)$ \\
\hline \multicolumn{2}{|c|}{ Therapy perceived as burdensome $(\mathrm{n}=791)$} \\
\hline Not at all & 1.0 \\
\hline A little & $0.73(0.45-1.17)$ \\
\hline A lot & $0.54(0.28-1.04)$ \\
\hline Very much & $1.15(0.52-2.57)$ \\
\hline \multicolumn{2}{|c|}{ Therapy being time-consuming $(\mathrm{n}=787)$} \\
\hline Not at all & 1.0 \\
\hline A little & $0.65(0.41-1.04)$ \\
\hline A lot & $0.76(0.42-1.40)$ \\
\hline Very much & $0.33(0.15-0.73)$ \\
\hline \multicolumn{2}{|c|}{ Experience of unpleasant side effects $(n=776)$} \\
\hline Not at all & 1.0 \\
\hline A little & $1.31(0.82-2.11)$ \\
\hline A lot & $0.83(0.44-1.56)$ \\
\hline Very much & $1.36(0.56-3.29)$ \\
\hline \multicolumn{2}{|c|}{ Realization of treatment recommendations $(n=792)$} \\
\hline Fully & 1.0 \\
\hline Mostly & $1.20(0.82-1.77)$ \\
\hline Hardly & $2.03(1.01-4.06)$ \\
\hline Not at all & $1.98(0.40-9.79)$ \\
\hline \multicolumn{2}{|l|}{ DLQI $(\mathrm{n}=798)$} \\
\hline No effect $(0-1)$ & 1.0 \\
\hline Small effect $(2-5)$ & $1.26(0.52-3.02)$ \\
\hline Moderate effect $(6-10)$ & $1.53(0.64-3.65)$ \\
\hline Very large effect $(11-20)$ & $3.00(1.21-7.37)$ \\
\hline Extremely large effect $(21-30)$ & $7.06(2.30-21.64)$ \\
\hline
\end{tabular}

$\mathrm{CI}=$ Confidence interval; $\mathrm{OR}=$ odds ratio. Bold indicates $\mathrm{p}<0.05$.

Difficulties in the realization of treatment recommendations were associated with severe itching, suggesting that the previous treatment of CHE had not sufficiently addressed itching. Another explanation may be that severe $\mathrm{CHE}$ is associated with more intense itch [16], which can complicate its treatment. One may also speculate that physicians tend to underestimate itch in CHE, leading to a reduced awareness and recording of this symptom, also in clinical studies.

Severity of itch in patients with CHE was significantly associated with impaired QoL (assessed by the DLQI) in a linear manner. Similar results were shown in patient populations affected by other skin diseases accompanied by itch, such as urticaria [25] and psoriasis [21, 26, 27]. One study investigating psychological factors associated with hand dermatoses showed that high stress responders stated significantly higher values for itch [28].

\section{Limitations}

In the CARPE registry, itch is only measured as one variable. As solely the presence of itch was asked, the results presented here refer to current itch. Details like course, localization and accompanying sensations like pain, burning or stinging would have been of interest as well. An assessment of itch according to the visual analogue scale is recommended for studies on itch [29, 30], but we relied on itch measured by a verbal rating scale. All findings presented in this paper are only representative for patients with CHE refractory to topical treatment. Because of the cross-sectional design of our study, caution needs to be exercised concerning suggestions about a causal relationship between the presence or severity of itch and the investigated variables. Further prospective and longitudinal studies may permit to establish a causal relationship. Our current analyses should be considered exploratory in nature. Nevertheless, these are the first findings on a variety of factors associated with the presence and severity of itch in patients with CHE.

\section{Disclosure Statement}

Christian Apfelbacher, Elke Weisshaar, Andrea Bauer, Peter Elsner and Thomas L. Diepgen received payments for consultations, conference travels and lectures from Basilea Pharmaceuticals and GlaxoSmithKline Germany. Jochen Schmitt received honoraria for CME certified educational tasks that received direct or indirect sponsoring from Basilea Pharmaceuticals and Novartis. He received funding for investigator initiated research from Novartis. Vera Mahler received lecturing fees from Basilea Pharmaceuticals and GlaxoSmithKline Germany. Sonja Molin acted as speaker, subinvestigator and consultant for and received honoraria or research support from Basilea Pharmaceuticals, Almirall and GlaxoSmithKline Germany. Linda Ruppert states no conflict of interest. The CARPE registry is funded by the German Dermatological Society (DDG). 


\section{References}

1 Diepgen TL, Andersen KE, Brandao FM, Bruze M, Bruynzeel DP, Frosch P, et al: Hand eczema classification: a cross-sectional, multicentre study of the aetiology and morphology of hand eczema. Br J Dermatol 2009;160:353358.

$>2$ Coenraads PJ: Hand eczema. N Engl J Med 2012;367:1829-1837.

3 Weisshaar E, Kallen U, Weiss M: 'The itching hand' - important differential diagnoses and treatment. J Dtsch Dermatol Ges 2013;11:3142.

4 Weisshaar E, Apfelbacher C, Jager G, Zimmermann E, Bruckner T, Diepgen TL, et al: Pruritus as a leading symptom: clinical characteristics and quality of life in German and Ugandan patients. Br J Dermatol 2006;155: 957-964.

$>5$ Weisshaar E, Dalgard F: Epidemiology of itch: adding to the burden of skin morbidity. Acta Derm Venereol 2009;89:339-350.

$\checkmark 6$ Matterne U, Apfelbacher CJ, Vogelgsang L, Loerbroks A, Weisshaar E: Incidence and determinants of chronic pruritus: a populationbased cohort study. Acta Derm Venereol 2013;93:532-537.

$>7$ Matterne U, Apfelbacher CJ, Loerbroks A, Schwarzer T, Buttner M, Ofenloch R, et al: Prevalence, correlates and characteristics of chronic pruritus: a population-based crosssectional study. Acta Derm Venereol 2011;91: 674-679.

8 Halvorsen JA, Kupfer A, Dalgard F: The prevalence and intensity of itch among dermatological patients in 13 European countries. Acta Derm Venereol 2013;93:620-621.

9 Apfelbacher CJ, Akst W, Molin S, Schmitt J, Bauer A, Weisshaar E, et al: CARPE: a registry project of the German Dermatological Society (DDG) for the characterization and care of chronic hand eczema. J Dtsch Dermatol Ges 2011;9:682-688.

10 Apfelbacher C, Molin S, Weisshaar E, Bauer A, Elsner P, Mahler V, et al: Characteristics and provision of care in patients with chronic hand eczema: updated data from the CARPE registry. Acta Derm Venereol 2014;94:163167.
11 Coenraads PJ, Van Der Walle H, ThestrupPedersen K, Ruzicka T, Dreno B, De La Loge $\mathrm{C}$, et al: Construction and validation of a photographic guide for assessing severity of chronic hand dermatitis. Br J Dermatol 2005; 152:296-301.

12 Diepgen TL, Sauerbrei W, Fartasch M: Development and validation of diagnostic scores for atopic dermatitis incorporating criteria of data quality and practical usefulness. J Clin Epidemiol 1996;49:1031-1038.

13 Hongbo Y, Thomas CL, Harrison MA, Salek MS, Finlay AY: Translating the science of quality of life into practice: what do dermatology life quality index scores mean? J Invest Dermatol 2005;125:659-664.

14 Sommer F, Hensen P, Bockenholt B, Metze D, Luger TA, Stander S: Underlying diseases and co-factors in patients with severe chronic pruritus: a 3-year retrospective study. Acta Derm Venereol 2007;87:510-516.

15 Dalgard F, Svensson A, Holm JO, Sundby J: Self-reported skin morbidity in Oslo. Associations with sociodemographic factors among adults in a cross-sectional study. Br J Dermatol 2004;151:452-457.

16 Boehm D, Schmid-Ott G, Finkeldey F, John SM, Dwinger C, Werfel T, et al: Anxiety, depression and impaired health-related quality of life in patients with occupational hand eczema. Contact Dermatitis 2012;67:184-192.

17 Stander S, Stumpf A, Osada N, Wilp S, Chatzigeorgakidis E, Pfleiderer B: Gender differences in chronic pruritus: women present different morbidity, more scratch lesions and higherburden. BrJ Dermatol 2013;168:1273-1280.

18 Verhoeven EW, Kraaimaat FW, van de Kerkhof PC, van Weel C, Duller P, van der Valk PG, et al: Prevalence of physical symptoms of itch, pain and fatigue in patients with skin diseases in general practice. Br J Dermatol 2007; 156:1346-1349.

19 Bilac C, Ermertcan AT, Bilac DB, Deveci A, Horasan GD: The relationship between symptoms and patient characteristics among psoriasis patients. Indian J Dermatol Venereol Leprol 2009;75:551.

20 Ghodsi SZ, Chams-Davatchi C, Daneshpazhooh M, Valikhani M, Esmaili N: Quality of life and psychological status of patients with pemphigus vulgaris using Dermatology Life Quality Index and General Health Questionnaires. J Dermatol 2012;39:141-144.
21 Reich A, Hrehorow E, Szepietowski JC: Pruritus is an important factor negatively influencing the well-being of psoriatic patients. Acta Derm Venereol 2010;90:257-263.

22 El-Baalbaki G, Razykov I, Hudson M, Bassel M, Baron M, Thombs BD, et al: Association of pruritus with quality of life and disability in systemic sclerosis. Arthritis Care Res (Hoboken) 2010;62:1489-1495.

23 Dalgard F, Kupfer J, Halvorsen JA: The burden of itch among dermatological patients in Europe. Acta Derm Venereol 2013;93:607608.

24 O’Neill JL, Chan YH, Rapp SR, Yosipovitch G: Differences in itch characteristics between psoriasis and atopic dermatitis patients: results of a web-based questionnaire. Acta Derm Venereol 2011;91:537-540.

-25 Zachariae R, Lei U, Haedersdal M, Zachariae $\mathrm{C}$ : Itch severity and quality of life in patients with pruritus: preliminary validity of a Danish adaptation of the itch severity scale. Acta Derm Venereol 2012;92:508-514.

26 Mabuchi T, Yamaoka H, Kojima T, Ikoma N, Akasaka E, Ozawa A: Psoriasis affects patient's quality of life more seriously in female than in male in Japan. Tokai J Exp Clin Med 2012;37:84-88.

-27 Nyunt WW, Low WY, Ismail R, Sockalingam $\mathrm{S}$, Min AK: Determinants of health-related quality of life in psoriasis patients in Malaysia. Asia Pac J Public Health 2013, Epub ahead of print.

28 Niemeier V, Nippesen M, Kupfer J, Schill WB, Gieler U: Psychological factors associated with hand dermatoses: which subgroup needs additional psychological care? Br J Dermatol 2002;146:1031-1037.

29 Reich A, Heisig M, Phan NQ, Taneda K, Takamori K, Takeuchi S, et al: Visual analogue scale: evaluation of the instrument for the assessment of pruritus. Acta Derm Venereol 2012;92:497-501.

30 Phan NQ, Blome C, Fritz F, Gerss J, Reich A, Ebata T, et al: Assessment of pruritus intensity: prospective study on validity and reliability of the visual analogue scale, numerical rating scale and verbal rating scale in 471 patients with chronic pruritus. Acta Derm Venereol 2012;92:502-507. 